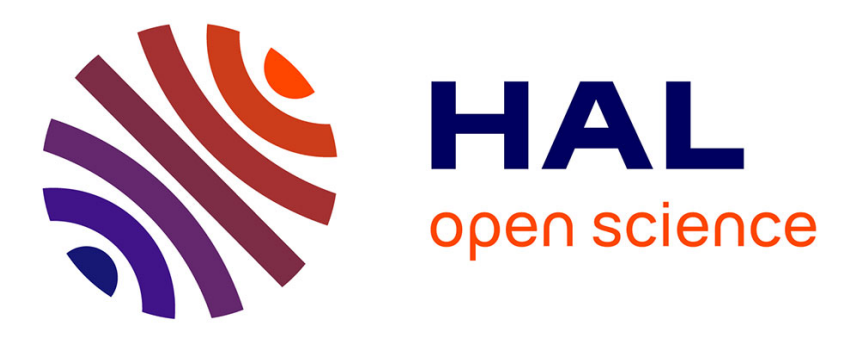

\title{
Changes in internal mechanical cost during over-ground running to exhaustion
}

\author{
Jean Slawinski, Veronique Billat
}

\section{To cite this version:}

Jean Slawinski, Veronique Billat. Changes in internal mechanical cost during over-ground running to exhaustion. Medicine and Science in Sports and Exercise, 2005, 37 (7), pp.1180-1186. 10.1249/01.mss.0000170101.99529.a3 . hal-01689815

\section{HAL Id: hal-01689815 https://hal-insep.archives-ouvertes.fr/hal-01689815}

Submitted on 22 Jan 2018

HAL is a multi-disciplinary open access archive for the deposit and dissemination of scientific research documents, whether they are published or not. The documents may come from teaching and research institutions in France or abroad, or from public or private research centers.
L'archive ouverte pluridisciplinaire HAL, est destinée au dépôt et à la diffusion de documents scientifiques de niveau recherche, publiés ou non, émanant des établissements d'enseignement et de recherche français ou étrangers, des laboratoires publics ou privés. 
Changes in internal mechanical cost during over-ground running to exhaustion.

SLAWINSKI JS ${ }^{1}$, BILLAT VL ${ }^{1}$, FACSM

${ }^{1}$ Department STAPS, UFR of Fundamental Applied Science University of Evry-Val d'Essonne, Bulding of Sciences François Mitterrand Street 91025 EVRY cedex, France.

Med. Sci. Sports Exerc., Vol. 37, No. 7, pp. 1180-1186, 2005.

Corresponding author: Slawinski Jean,

Address for correspondence: Department STAPS, UFR of Fundamental Applied Science University of Evry-Val d'Essonne, Bulding of Sciences François Mitterrand Street 91025 EVRY cedex, France.

Phone : +33.1 .43 .29 .27 .18$

Fax : +33.1.42.39.20.83

E-mail : jeanslawinski@yahoo.fr

Running title: Fatigue and biomechanics of running. 


\section{Abstract}

Objective: The purpose of this study was to determine, during an over-ground suprathreshold run, whether a change in the internal mechanical cost could occur during an exhaustive run and if this change was related to the increase in the energy cost of running $\left(\mathrm{C}_{\mathrm{r}}\right)$. Methods: The $\mathrm{C}_{\mathrm{r}}$ of fourteen endurance runners was measured from pulmonary gas exchange using a breath by breath portable gas analyser (Cosmed $\mathrm{K} 4 \mathrm{~b}^{2}$, Roma, Italy), at the third and the last minute of an exhaustive exercise performed at their velocity corresponding to $95 \%$ of the maximal oxygen uptake (4.88 $\left.\pm 0.38 \mathrm{~m} \cdot \mathrm{s}^{-1}\right)$. At the same time, potential, kinetic and internal mechanical costs $\left(\mathrm{C}_{\mathrm{pe}}\right.$, $\mathrm{C}_{\mathrm{ke}}$ and $\mathrm{C}_{\mathrm{int}}$ ) were measured with a 3D motion analysis system (ANIMAN3D). Results: $C_{\text {int }}$ and $C_{r}$ increased significantly within the $3^{\text {rd }}$ minute and the end of the supra-threshold exercise (respectively $0.55 \pm 0.07$ vs $0.60 \pm 0.07 \mathrm{~J}^{\mathrm{kg}}{ }^{-1} \cdot \mathrm{m}^{-1}$ and $4.10 \pm$

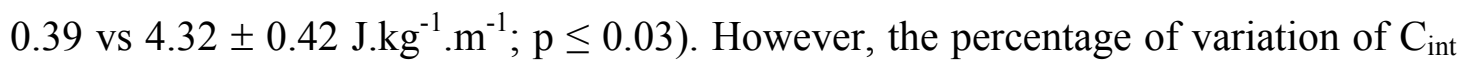
and $\mathrm{C}_{\mathrm{r}}$ were not correlated $(\mathrm{r}=0.06 ; \mathrm{p}=0.84)$. Contrary to $\mathrm{C}_{\mathrm{int}}, \mathrm{C}_{\mathrm{ke}}$ and $\mathrm{C}_{\mathrm{pe}}$ remained constant during the exercise (respectively $1.33 \pm 0.33$ vs $1.38 \pm 0.29 \mathrm{~J} \mathrm{~kg}^{-1} \cdot \mathrm{m}^{-1} \mathrm{p}=$ 0.79 and $0.47 \pm 0.11$ vs $0.48 \pm 0.10 \mathrm{~J}_{\mathrm{kg}}{ }^{-1} \cdot \mathrm{m}^{-1} ; \mathrm{p}=0.67$ ), but both parameters were significantly correlated with $\mathrm{C}_{\mathrm{r}}(\mathrm{r}=-0.43 ; \mathrm{p}=0.03$ and $\mathrm{r}=0.40 ; \mathrm{p}=0.03)$. Conclusion: During over-ground running to exhaustion a significant increase in $\mathrm{C}_{\mathrm{int}}$ occurred, but this did not account for the increase in $\mathrm{C}_{\mathrm{r}}$. Moreover, the increase in $\mathrm{C}_{\mathrm{int}}$ has yet to be explained.

Key words: Energy cost, oxygen slow component, mechanical work and fatigue. 


\section{Introduction}

\section{Paragraph Number 1}

The process of determining the energy cost of running $\left(\mathrm{C}_{\mathrm{r}}\right)$ during an exercise of moderate intensity is based on two assumptions. The first is that $\mathrm{C}_{\mathrm{r}}$ is independent of running time for constant-speed running of 3-30 minutes duration. The second is that a steady-state of oxygen uptake ( $\left.\mathrm{V}_{2}\right)$ occurs following 3-4 min of exercise (25). However, during constant-load exercise of supra-lactic threshold intensity, the steadystate of $\dot{\mathrm{VO}}_{2}$ is delayed after 3-4 min. A number of physiological factors have been postulated as contributing to this delayed steady state of $\dot{\mathrm{VO}}_{2}$ during a supra-lactic threshold exercise $(8,13,20)$. However, biomechanical factors have received less attention as potential causes which could partially explain this increase in $\mathrm{C}_{\mathrm{r}}$.

\section{Paragraph Number 2}

In running studies, biomechanical factors have often been used to address the differences in $\mathrm{C}_{\mathrm{r}}$ among individuals $(17,35)$. Kram (22), as well as Farley and McMahon (19), had shown that $C_{r}$ could be determined by the force generated by the muscle during running. Others have also shown that an inverse relationship exists between the stiffness of the body and the $\mathrm{C}_{\mathrm{r}}(15)$. However, the interactions between mechanical and metabolic variables appear to be very complex. A general mechanical approach has been based on the observation of the mechanical energy change of the centre of mass and of the limbs of the body $(14,34)$. Indeed, the mechanical energy change associated with the movement of the different segments of the body during running, represents the energy used by the active muscle. Poole et al. (26) have demonstrated that $86 \%$ of this increase in $\mathrm{C}_{\mathrm{r}}$ was related to the increase in active muscle $\dot{\mathrm{V}} \mathrm{O}_{2}$. Therefore the increase in $\mathrm{C}_{\mathrm{r}}$ observed at the end of supra lactic threshold exercise may be related to the variation in mechanical energy. 


\section{Paragraph Number 3}

Some studies have significantly related the differences in $\mathrm{C}_{\mathrm{r}}$ to the energy variations of the centre of mass during running $(11,12)$. Above the lactic threshold and under the influence of fatigue, the mechanical cost associated with the movements of an anatomical point taken as equivalent of the body centre of mass of the runner, has been significantly correlated with $\mathrm{C}_{\mathrm{r}}$ and increased significantly between the beginning and the end of the exercise (12). Even if the interactions between biomechanical and physiological factors are still open to debate, this result suggests that the increase in $C_{r}$, generally observed after the $3^{\text {rd }}$ min of a supra-lactic threshold exercise, may be due to a combined action of both physiological and mechanical mechanisms. Recently, Borrani et al. (10) and Avogadro et al. (2) suggested that the increase in $\mathrm{C}_{\mathrm{r}}$ in running did not result from a change in the external mechanical cost under the effect of fatigue. Nevertheless, the decrease in stride frequency suggested an alternative mechanical explanation such as a modification of the mechanical cost associated with the movements of the limbs around the centre of mass which is called the internal mechanical cost $\left(\mathrm{C}_{\mathrm{int}}\right)$.

\section{Paragraph Number 4}

Therefore, in order to complete the understanding of the relationship between mechanical and metabolic variables, this study aims to determine whether a change in $\mathrm{C}_{\text {int }}$ could occur during an exhausting over-ground run and whether this change is related to a modification of $C_{r}$. The hypothesis was that the increase in $C_{r}$, generally observed after the $3^{\text {rd }}$ min of a supra-lactic threshold exercise, is associated with a modification of $\mathrm{C}_{\text {int }}$. 


\section{Paragraph Number 5}

\section{Methods}

\section{Subjects and protocol}

Fourteen subjects (mean height $1.73 \pm 0.06 \mathrm{~m}$, mean body mass $62 \pm 9 \mathrm{~kg}$, and mean age $21.9 \pm 2.8 \mathrm{yrs}$ ) volunteered to participate in this study. This population was composed of 3 females and 11 males. Five subjects were physical education students (soccer, rugby and tennis players), the others subjects trained regularly in running (they had a national or a regional level of competition). Table 1 summarises this information. Prior to participation, all the subjects were informed of risks and stress associated with the experimental protocol and gave a written voluntary informed consent and approval received by ethics committee in accordance with the guidelines of the hospital of Paris $\mathrm{S}^{\mathrm{t}}$ Louis.

\begin{tabular}{c|c|c|c}
\hline & $\begin{array}{c}\text { Specialist of running } \\
(\boldsymbol{n}=\mathbf{9})\end{array}$ & $\begin{array}{c}\text { Non specialist of running } \\
(\boldsymbol{n}=\mathbf{5})\end{array}$ & $\begin{array}{c}\text { Total } \\
(\boldsymbol{n}=\mathbf{1 4})\end{array}$ \\
\hline$v \dot{V} O_{2 \max }\left({\left.\mathrm{m} . \mathrm{s}^{-1}\right)}_{\dot{V} O_{2 \max }}\right.$ & $5.31 \pm 0.34$ & $4.75 \pm 0.35^{\dagger}$ & $5.10 \pm 0.43$ \\
$\left(\mathrm{ml} . \mathrm{kg}^{-1} . \mathrm{min}^{-1}\right)$ & $57.1 \pm 8.5$ & $67.6 \pm 6.3^{\dagger}$ & $63.8 \pm 8.6$ \\
$v L T\left(\mathrm{~m}^{-1}\right)$ & $4.43 \pm 0.46$ & $3.70 \pm 0.45^{\dagger}$ & $4.23 \pm 0.55$ \\
tlim $(\mathrm{s})$ & $369.8 \pm 52.7$ & $374.4 \pm 90.8$ & $372.8 \pm 77.0$ \\
Height $(\mathrm{m})$ & $1.72 \pm 0.06$ & $1.74 \pm 0.05$ & $1.73 \pm 0.06$ \\
Age $(\mathrm{yr})$ & $20.4 \pm 2.1$ & $24.6 \pm 1.5^{\dagger}$ & $21.9 \pm 2.8$ \\
Body mass $(\mathrm{kg})$ & $58.9 \pm 8.1$ & $68.6 \pm 7.2^{\dagger}$ & $62.4 \pm 8.9$ \\
\hline
\end{tabular}

Significantly different from the specialist of running $(p \leq 0.05)$.

Table 1: Anthropometrical and physiological variables of the fourteen subjects: the maximal oxygen uptake ( $\left.\dot{\mathrm{VO}}_{2 \max }\right)$, the velocity associated to $\dot{\mathrm{V}}{ }_{2 \max }\left(\mathrm{v} \dot{\mathrm{VO}}{ }_{2 \max }\right)$, the velocity at the lactate threshold (vLT) and time to exhaustion (tlim).

All subjects performed two exhaustive tests.

- An incremental test (3-min stages) to exhaustion (the voluntary stop of the exercise). This test was performed on a track in order to determine the maximal oxygen consumption $\left(\dot{\mathrm{VO}}_{2 \text { max }}\right)$. This parameter was defined as the highest $30 \mathrm{~s}$ 
$\dot{\mathrm{VO}}_{2}$ value attained during the test. The velocity associated with $\dot{\mathrm{VO}}_{2 \text { max }}$ $\left(\mathrm{v} \dot{\mathrm{VO}}_{2 \max }\right)(9)$. The velocity at the lactate threshold (vLT) was defined as the speed measured at $\dot{\mathrm{VO}}_{2}$ value which corresponds to the starting point of an accelerated lactate accumulation between 3.5 and $5 \mathrm{mmol} . \mathrm{L}^{-1}(1)$.

- An exhaustive run at $95 \%$ of $\mathrm{v} \dot{\mathrm{V} O}{ }_{2 \max }$ until exhaustion (tlim95). Throughout the tests, the subjects adopted the required velocity using an audio rhythm which gave the time to cover $20-\mathrm{m}$. Visual marks were set at $20-\mathrm{m}$ intervals along the track with audio signals determining the speed needed to cover 20 -m intervals. To estimate the kinetic, potential and internal mechanical cost of running $\left(\mathrm{C}_{\mathrm{ke}}, \mathrm{C}_{\mathrm{pe}}\right.$ and $\left.\mathrm{C}_{\mathrm{int}}\right)$, the mechanical analysis was performed during the tlim95. The runners were filmed by a video camera using a sampling frequency of 25 frames per second (Sony, Beta SP VCRs, resolution of 572 lines). The camera was positioned 9 meters from the left of the runner. Two consecutives steps were analysed at the beginning of the test (during the second lap of the track, around the $3^{\text {rd }}$ min after the beginning of the exercise) and two more steps at the end of the test (during the last lap of track, around the last minute of the exercise). The running speed was documented with the video camera, for each time the runner crossed in front of the camera (Table 2). The energetic cost of running $\left(C_{r}\right)$ was also evaluated throughout the exercise, by the oxygen uptake measurement. 


\begin{tabular}{|c|c|c|}
\hline & $\begin{array}{l}3^{r d} \min \\
(n=14)\end{array}$ & $\begin{array}{c}\text { End } \\
(n=14)\end{array}$ \\
\hline Velocity $\left(m \cdot s^{-1}\right)$ & $4.87 \pm 0.40$ & $4.89 \pm 0.37$ \\
\hline$S R(H z)$ & $2.98 \pm 0.12$ & $3.00 \pm 0.16$ \\
\hline$S L(m)$ & $1.62 \pm 0.14$ & $1.63 \pm 0.11$ \\
\hline$C_{k e}\left(j \cdot \mathrm{kg}^{-1} \cdot \mathrm{m}^{-1}\right)$ & $1.33 \pm 0.33$ & $1.38 \pm 0.29$ \\
\hline$C_{p e}\left(j \cdot \mathrm{kg}^{-1} \cdot \mathrm{m}^{-1}\right)$ & $0.47 \pm 0.11$ & $0.48 \pm 0.10$ \\
\hline$C_{\text {int }}\left(j \cdot \mathrm{kg}^{-1} \cdot \mathrm{m}^{-1}\right)$ & $0.55 \pm 0.07$ & $0.60 \pm 0.07^{\dagger}$ \\
\hline$C_{r}\left(j \cdot \mathrm{kg}^{-1} \cdot \mathrm{m}^{-1}\right)$ & $4.10 \pm 0.39$ & $4.32 \pm 0.42^{\dagger}$ \\
\hline
\end{tabular}

'Significantly different from the $3^{\text {rd }}$ minute of the exercise ( $\left.p \leq 0.05\right)$.

Table 2: Changes in the stride rate (SR), the stride length (m), the velocity of the exercise, kinetic $\left(\mathrm{C}_{\mathrm{ke}}\right)$, potential $\left(\mathrm{C}_{\mathrm{pe}}\right)$, internal mechanical cost $\left(\mathrm{C}_{\mathrm{pe}}\right)$ and energetic cost of running $\left(\mathrm{C}_{\mathrm{r}}\right)$ between the $3^{\text {rd }}$ and the last minute of the exercise.

\section{Paragraph Number 6}

\section{Material}

Oxygen uptake measurement. Throughout the exercises, the respiratory and pulmonary gas exchange variables were measured using a breath-by-breath portable gas analyzer (Cosmed $\mathrm{K}_{4} \mathrm{~b}^{2}$, Roma, Italy). Before each test, $\mathrm{O}_{2}$ and $\mathrm{CO}_{2}$ analysers were calibrated using ambient air and sample gas references of $16 \% \mathrm{O}_{2}$ and $5 \% \mathrm{CO}_{2}$. The flowmeter was calibrated with a volume of air of 3-1 (Quinton instruments, Seattle, USA). The accuracy of this system has been tested and is acceptable for $\dot{\mathrm{V}}_{2}$ and $\dot{\mathrm{V} C O} \mathrm{O}_{2}$ measurement during supra-lactic threshold exercise (23).

\section{Paragraph Number 7}

Mechanical measurement. The video sequences obtained during the tlim95 were digitised without distortion on a $\mathrm{PC}$ as a series of bitmap images by a Perception Video Recorder card from Silicon Co. Then the images recorded were displayed and analysed on a screen of a regular PC. ANIMAN 3D uses the numerical human model MAN3D $(27,28,30)$ which is delimited by an envelope composed of 155 crowns. These crowns are superimposed on the different segments of the manikin (figure 1). The position and posture of MAN3D can be adjusted to each runner. The 
morphological properties of MAN3D are deduced from the size and the weight of the subject. The inertial properties of the segments are from works of Dempster and Gaughran (16). Then MAN3D is projected onto images. When the projections of MAN3D were superimposed onto the images of the runner, the position and posture of the runner were the same as that of MAN3D. Posture and position adjustments were optimized by locating the positions of some particular points of the runner on the images which must coincide with some equivalent points of MAN3D. There are 5 particulars points which help the researcher to project Man3D on the runner. These points are represented in the following picture (figure 2):

- The top of the head.

- The hand in direct view.

- $\quad$ Two points on the back.

- The end of the foot in direct view.

Our method has been compared with the measure of a force plate-form (29). The results have shown that the difference between both systems on the computation of the mechanical energy was about $11 \%$ and remains constant for different running speeds. When the segments (hand, forearm and arm) are out of direct view, the system allows Man3D to be projected onto a partially hidden segment with accuracy. Indeed, when the elbow is in direct view, it is possible to deduce the position of the forearm and of the arm with accuracy. However, when the elbow and the forearm is out of direct view (as in figures 1 or 2) the system does not allow one to deduce with the same accuracy the position of the hand, the forearm or the arm. But this case (when the arm is totally hidden) does not represent more than one or two images during one step. Moreover, the position of the hidden arm can be deduced from the previous and the following positions of the arm. This procedure allows the trajectory of the body centre of mass 
and the trajectories of the limb centres of mass to be obtained. The uncertainty in the determination of the different centres of mass trajectories depends on the resolution of the video camera used.

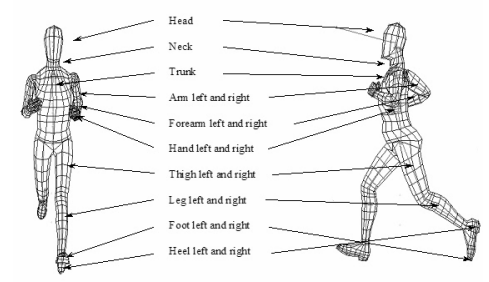

Figure 1: MAN3D human model representation and its 17 segments.

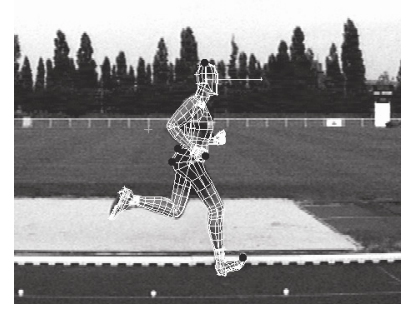

Figure 2: Example of projection of Man 3D on the runner, with the 5 particulars points (black).

\section{Paragraph Number 8}

\section{Data analysis}

Energy cost $\left(\mathrm{C}_{\mathrm{r}}\right)$. The breath-by-breath oxygen uptake data were reduced to 5 -s stationary averages in order to reduce the noise so as to enhance the oxygen kinetics characteristics. These data were finally fitted to two exponential functions using a least square fit method: a single-exponential function comprising a delayed linear component (eq. 1) and a double-exponential function comprising two exponential terms which start at two distinct time delays from the onset of exercise (eq. 2) (4). The Fisher test was used to choose the model for which the fit was associated with the highest $F$ value (4).

$$
\dot{\mathrm{V}} \mathrm{O}_{2}(\mathrm{t})=\mathrm{y}_{0}+\mathrm{A}_{1} \times\left(1-\mathrm{e}^{-(\mathrm{t}-\mathrm{TD} 1) / \tau_{1}}\right) \times \mathrm{U}_{1}
$$


(fast component)

$+\mathrm{A}_{2} \times\left(1-\mathrm{e}^{-(\mathrm{t}-\mathrm{TD} 2) / \tau_{2}}\right) \times \mathrm{U}_{2}$

(slow component)

Where $\mathrm{y}_{0}$ is the baseline $\dot{\mathrm{VO}}_{2}\left(\mathrm{ml} \cdot \mathrm{min}^{-1}\right), \mathrm{A}_{1}$ and $\mathrm{A}_{2}$ are the asymptotic amplitudes for the exponential terms $\left(\mathrm{ml}^{\mathrm{min}}{ }^{-1}\right), \tau_{1}$ and $\tau_{2}$ are the time constants (min), and TD1 and $\mathrm{TD} 2$ are the time delay from the onset of exercise (s).

$$
\begin{aligned}
& \mathrm{U}_{1}=0 \text { for } \mathrm{t}<\mathrm{TD} 1 \text { and } \mathrm{U}_{1}=1 \text { for } \mathrm{t} \geq T \mathrm{TD} 1 \\
& \mathrm{U}_{2}=0 \text { for } \mathrm{t}<\mathrm{TD} 2 \text { and } \mathrm{U}_{2}=1 \text { for } \mathrm{t} \geq \mathrm{TD} 2
\end{aligned}
$$

The energy cost of running $\left(\mathrm{C}_{\mathrm{r}}\right)$ was evaluated, 3 mins after the beginning of the exercise and 1 min before its end (12):

$\mathrm{C}_{\mathrm{r}}=\dot{\mathrm{V}} \mathrm{O}_{2}(\mathrm{t}) \cdot \mathrm{E}_{\mathrm{O}_{2}} \cdot \mathrm{V}_{95}^{-1} \cdot \mathrm{M}^{-1}$

Where $\mathrm{E}_{\mathrm{O}_{2}}\left(21.3 \mathrm{~J} \cdot \mathrm{mlO}_{2}^{-1}\right)$ is the energy equivalent of $1 \mathrm{mlO}_{2}$ for a respiratory exchange ratio of 1 (12), and $\mathrm{V}_{95}$ is the velocity during the test tlim95 (measured with the video camera).

Paragraph Number 9

Mechanical cost. All the trajectories of the different centres of mass of the model (segments and body centres of mass) were smoothed using a polynomial method in order to obtain by derivation the speed displacement of the different centres of mass. The speed of running was measured with the video camera after the trial. In the referential of the camera, the horizontal position of the CM increases linearly according to time (figure 3). The slope of the relationship between time and the horizontal position of the $\mathrm{CM}$ allows one to calculate the speed of the $\mathrm{CM}$ of the runner. Moreover, the speed was measured with photo cells placed in the field of the camera. The polynomial method used was a polynomial of high multiple order. After 
plotting the residual according to the order of the polynomial (37), the polynomial degree was determined individually for the trajectory of the centre of mass of each subject. Variations of potential and kinetic energies $\left(\Delta \mathrm{E}_{\mathrm{pe}}\right.$ and $\Delta \mathrm{E}_{\mathrm{ke}}$ respectively) were then calculated (in joules).

$$
\begin{aligned}
& \Delta \mathrm{E}_{\mathrm{pe}}=\mathrm{M} \times \mathrm{g} \times\left(\mathrm{H}_{\text {max }}-\mathrm{H}_{\text {min }}\right) \\
& \Delta \mathrm{E}_{\mathrm{ke}}=\frac{1}{2} \mathrm{M} \times\left(\mathrm{V}_{\text {max }}^{2}-\mathrm{V}_{\text {min }}^{2}\right)
\end{aligned}
$$

"M" is the body mass $(\mathrm{kg})$, " $\mathrm{g}$ " is the gravitational acceleration $\left(9.81 \mathrm{~m} \cdot \mathrm{s}^{-2}\right)$, " $\mathrm{H}_{\max }$ and $\mathrm{H}_{\text {min }}$ " are maximal and minimal heights of the body centre of mass (CM) during one step (m). " $\mathrm{V}_{\max }$ and $\mathrm{V}_{\min }$ " are the maximal and minimal horizontal velocities of the CM during one step $\left(\mathrm{m} \cdot \mathrm{s}^{-1}\right)$.

\section{Paragraph Number 10}

The internal energy $\left(E_{\text {int }}\right)$ represents the sum of the mechanical energies associated with the different segments of the body. The present model used in this work (figure $1)$ is composed of 17 different segments. The variation of internal energy $\left(\Delta \mathrm{E}_{\text {int }}\right)$ is calculated as the maximal minus the minimal $\mathrm{E}_{\text {int }}$ during the step.

$$
\mathrm{E}_{\text {int }}=\frac{1}{2} \sum_{\mathrm{i}=1}^{17}\left(\mathrm{~m}_{\mathrm{s}} \mathrm{V}_{\mathrm{s}}^{2}+\mathrm{I}_{\mathrm{s}} \omega_{\mathrm{s}}^{2}\right)
$$

Where "s" represents a segment, " $\mathrm{m}_{\mathrm{s}}$ " is the mass of the segment $(\mathrm{kg})$ considered and "I $\mathrm{s}_{\mathrm{s}}$ " is the moment of inertia of the segment $\left(\mathrm{kg} \cdot \mathrm{m}^{2}\right)$. " $\mathrm{V}_{\mathrm{s}}$ " is the velocity of the centre

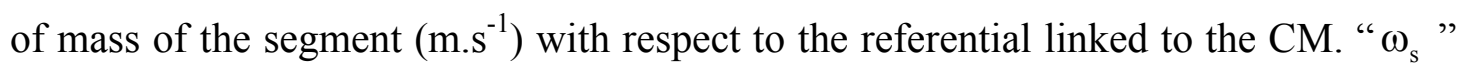
is the angular velocity of the centre of mass of the segment $\left(\mathrm{rad} . \mathrm{s}^{-1}\right)$ with respect to the referential linked to the $\mathrm{CM}$ of the segment. 
Kinetic, potential and internal mechanical cost expressed in $\mathrm{J}_{\mathrm{kg}} \mathrm{k}^{-1} \cdot \mathrm{m}^{-1}\left(\mathrm{C}_{\mathrm{ke}}, \mathrm{C}_{\mathrm{pe}}, \mathrm{C}_{\mathrm{int}}\right)$ are equal to the positive variation of $E_{k e}, E_{p e}$ and $E_{\text {int }}$ during one step, divided by the mass and the step amplitude of the subject.

The step rate (SR) was computed by counting the number of images for a stride and the step length (SL) was computed by dividing the running speed by SR.

The percentages of variation between the $3^{\text {rd }}$ min and the end of the exercise of $C_{r}$ and $\mathrm{C}_{\text {int }}$, were also calculated $\left(\% \Delta \mathrm{C}_{\mathrm{r}}\right.$ and $\left.\% \Delta \mathrm{C}_{\text {int }}\right)$.

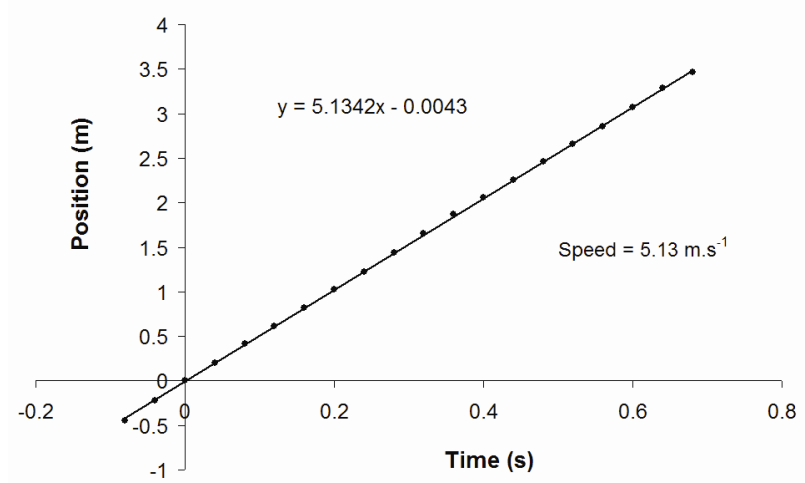

Figure 3: Example of horizontal position of the $\mathrm{CM}$ in the referential of the camera, and calculus of the speed of the $\mathrm{CM}$ of the runner.

\section{Paragraph Number 11}

\section{Statistics}

Relationships between the $\mathrm{C}_{\mathrm{r}}$ and $\mathrm{C}_{\mathrm{pe}}, \mathrm{C}_{\mathrm{ke}}$ or $\mathrm{C}_{\mathrm{int}}$ were determined by standard linear regression and tested using a Spearman test. A paired Student test was also used in order to compare the average values for the velocity, the stride rate (SR), the stride length (SL), $\mathrm{C}_{\mathrm{pe}}, \mathrm{C}_{\mathrm{ke}}, \mathrm{C}_{\mathrm{int}}$ and $\mathrm{C}_{\mathrm{r}}$ obtained at the beginning and at the end of the tlim95 test. The runners were grouped by level of experience in running (specialist and nonspecialist) and a Student test was use to compare both populations. The significance level was fixed at $\mathrm{P}=0.05$. 


\section{Results}

During the constant load exercise, the subjects ran for $373 \pm 77 \mathrm{~s}$ before exhaustion at a velocity of $17.6 \pm 1.4 \mathrm{~km} \cdot \mathrm{h}^{-1}\left(4.88 \pm 0.38 \mathrm{~m} \cdot \mathrm{s}^{-1}\right)$. During this constant load exercise, the energy cost of running $\left(\mathrm{C}_{\mathrm{r}}\right)$ increased significantly within the $3^{\text {rd }}$ and the last minute (table 2).

\section{Paragraph Number 13}

Within the $3^{\text {rd }}$ and the last minute of exercise the velocity of running, the stride rate (SR) and the stride length (SL) did not vary significantly (table 2). At the same time, $\mathrm{C}_{\mathrm{ke}}$ and $\mathrm{C}_{\mathrm{pe}}$ also remained constant (table 2). Indeed, $\mathrm{C}_{\mathrm{ke}}$ varied from $1.33 \pm 0.33{\mathrm{~J} . \mathrm{kg}^{-}}^{-}$ ${ }^{1} \cdot \mathrm{m}^{-1}$ to $1.38 \pm 0.29 \mathrm{~J} \cdot \mathrm{kg}^{-1} \cdot \mathrm{m}^{-1}(\mathrm{P}=0.78)$ and $\mathrm{C}_{\mathrm{pe}}$ varied from $0.47 \pm 0.11 \mathrm{~J} \cdot \mathrm{kg}^{-1} \cdot \mathrm{m}^{-1}$ to $0.48 \pm 0.10 \mathrm{~J} \cdot \mathrm{kg}^{-1} \cdot \mathrm{m}^{-1}(\mathrm{P}=0.67)$. These results demonstrated that during track running there was no modification of $\mathrm{SR}, \mathrm{C}_{\mathrm{ke}}$ or $\mathrm{C}_{\mathrm{pe}}$ at the end of an exhaustive exercise.

Paragraph Number 14

However, significant correlations have been established between $\mathrm{C}_{\mathrm{r}}$ and $\mathrm{C}_{\mathrm{ke}}$ or $\mathrm{C}_{\mathrm{pe}}(\mathrm{r}=$ 0.43 and $\mathrm{P}=0.03 ; \mathrm{r}=0.40$ and $\mathrm{P}=0.03$; figure $4 \mathrm{~A}, \mathrm{~B})$. They only explained 18 to $16 \%$ variance between measures. Therefore, such as it was calculated in the present work, $\mathrm{C}_{\mathrm{ke}}$ or $\mathrm{C}_{\mathrm{pe}}$ constituted a global descriptor of the $\mathrm{C}_{\mathrm{r}}$.

Paragraph Number 15

The internal mechanical cost $\left(\mathrm{C}_{\mathrm{int}}\right)$, contrary to $\mathrm{C}_{\mathrm{ke}}$ and $\mathrm{C}_{\mathrm{pe}}$, increased significantly between the $3^{\text {rd }}$ and the last minute of the exercise $(\mathrm{P} \leq 0.05$, table 2$)$. The average percentage of variation of $\mathrm{C}_{\text {int }}\left(\% \Delta \mathrm{C}_{\text {int }}\right)$ was $9.7 \%$ with a great inter-individual variability. Indeed, eleven runners presented an increase of $\mathrm{C}_{\mathrm{int}}$, (comprised) of between 4 and $35 \%$ and 3 runners presented a decrease of $\mathrm{C}_{\mathrm{int}}$ (comprised) of between -4 and $-15 \%$. Moreover, no correlation was observed between $\mathrm{C}_{\mathrm{int}}$ and $\mathrm{C}_{\mathrm{ke}}, \mathrm{C}_{\mathrm{pe}} \mathrm{SR}$ or SL (respectively, $\mathrm{r}=0.07$ and $\mathrm{P}=0.73 ; \mathrm{r}=-0.2$ and $\mathrm{P}=0.31 ; \mathrm{r}=0.06$ and $\mathrm{P}=0.77 ; \mathrm{r}$ 
$=0.13$ and $\mathrm{P}=0.50$ ). This result showed that the increase of $\mathrm{C}_{\text {int }}$ was not associated to a modification of other mechanical parameters. However, the percentage of variation of $\mathrm{C}_{\mathrm{int}}\left(\% \Delta \mathrm{C}_{\mathrm{int}}\right)$ was significantly different between the specialist and the non specialist of running $(p=0.03)$. Indeed, the non specialists increase $C_{\text {int }}$ by $20 \%$, within the $3^{\text {rd }}$ and the last minute of exercise, while the specialists do not increase it $(4 \%)$.

Finally, there was no correlation between the $\mathrm{C}_{\mathrm{r}}$ and $\mathrm{C}_{\text {int }}$ (figure $4 \mathrm{C}$ ) or between $\% \Delta \mathrm{Cr}$ and $\% \Delta \operatorname{cint}(\mathrm{r}=0.06 ; \mathrm{P}=0.84)$. The increase in $\mathrm{C}_{\mathrm{r}}$ observed after the $3^{\mathrm{rd}}$ min of a supra-lactic threshold exercise is not associated with a modification of $\mathrm{C}_{\mathrm{int}}$. 

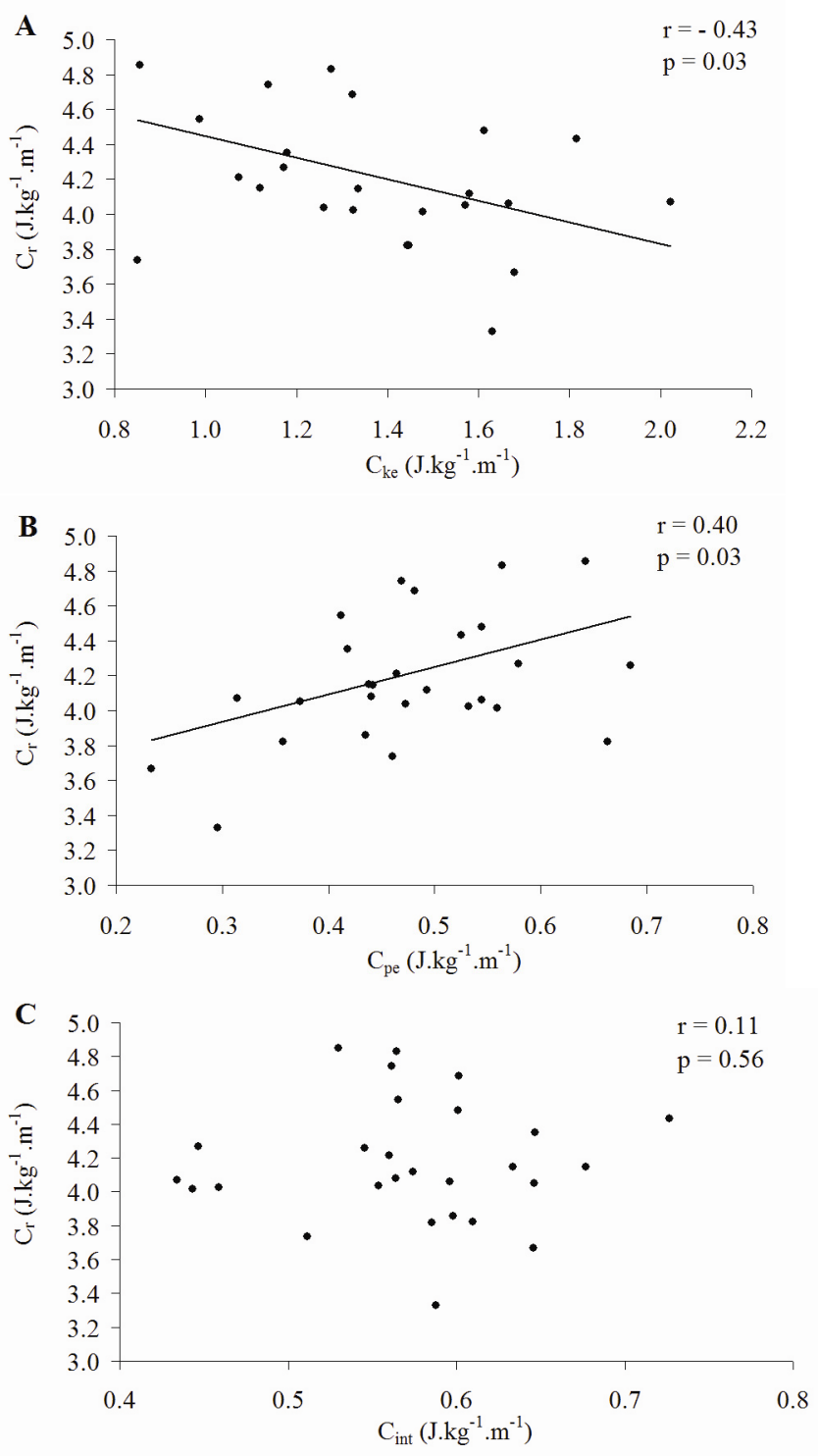

Figure 4: Correlation, between $\mathrm{C}_{\mathrm{r}}$ and $\mathrm{C}_{\mathrm{ke}}(\mathrm{A}), \mathrm{C}_{\mathrm{pe}}(\mathrm{B})$ and $\mathrm{C}_{\mathrm{int}}(\mathrm{C})$ measured in the fourteen runners, at the $3^{\text {rd }}$ and the last minute of the exhausting exercise.

\section{Paragraph Number 16}

\section{Discussion}

This study aims to test the hypothesis that the increase in the energy cost generally observed at the end of a supra-lactate threshold run was associated with a modification in the internal mechanical cost of running. This study showed that during track running, exhaustion has no effect on $\mathrm{C}_{\mathrm{pe}}$ or $\mathrm{C}_{\mathrm{ke}}$. Despite the fact that both $\mathrm{C}_{\mathrm{r}}$ and $\mathrm{C}_{\mathrm{int}}$ increase, $\mathrm{C}_{\mathrm{r}}$ is only correlated with $\mathrm{C}_{\mathrm{ke}}$ and $\mathrm{C}_{\mathrm{pe}}$, and not with $\mathrm{C}_{\text {int }}$. Thus, this slight 
increase in $\mathrm{C}_{\mathrm{r}}$ is not associated with a modification of the mechanical work produced in running.

Paragraph Number 17

In the present study, during the supra-threshold exhaustive run, $\mathrm{C}_{\mathrm{r}}$ increased within the $3^{\text {rd }}$ and the last minute of the exercise. This increase in $C_{r}$ has been well documented $(20,38)$ and depends on the physiological adaptations which are linked to the oxygen slow component. Indeed, several studies have reported the appearance of a $\dot{\mathrm{V}} \mathrm{O}_{2}$ slow component after the $3^{\text {rd }}$ min of exercise above the lactate threshold $(3,8,13,33)$. This $\dot{\mathrm{V}} \mathrm{O}_{2}$ slow component explains this increase up to exhaustion of $\mathrm{C}_{\mathrm{r}}(6)$. A number of metabolic factors have been postulated as contributing to this $\dot{\mathrm{V}}_{2}$ slow component (see for review Gaesser and Poole (20); Xu and Rhode (38)).

Paragraph Number 18

This increase in $\mathrm{C}_{\mathrm{r}}$ between the $3^{\mathrm{rd}}$ and the last minute of exercise is not accompanied by an increase of $\mathrm{C}_{\mathrm{ke}}$ and $\mathrm{C}_{\mathrm{pe}}$. Therefore the increase in $\mathrm{C}_{\mathrm{r}}$ cannot be related to $\mathrm{C}_{\mathrm{ke}}$ or $\mathrm{C}_{\mathrm{pe}}$. Following the idea that smaller vertical oscillation of the centre of mass is associated with a low $C_{r}$, there was a significant correlation between $C_{r}$ and $C_{p e}$ (figure 4B). As already demonstrated in the literature $(11,12)$, low but significant correlations have been established between $C_{r}$ and $C_{k e}$ or $C_{p e}$ (figure $4 A$ and $B$ ). Although there was a significant correlation between $\mathrm{C}_{\mathrm{r}}$ and $\mathrm{C}_{\mathrm{ke}}$ or $\mathrm{C}_{\mathrm{pe}}$, the increase in $\mathrm{C}_{\mathrm{r}}$ could not be related to the mechanical cost associated with the movements of the centre of mass during the step.

\section{Paragraph Number 19}

A detailed analysis of mechanical data showed that the mechanical cost associated with the movements of the limbs around the centre of mass $\left(\mathrm{C}_{\mathrm{int}}\right)$ increases significantly by $9.7 \%$ within the $3^{\text {rd }}$ and the last minute of the exercise. This increase 
in $\mathrm{C}_{\text {int }}$ during track running has never been described and depends on mechanical adaptations which have yet to be explained. Numerous factors influence $C_{\text {int }}$, speed (34), load, gradient, gait, or stride frequency (24). In order to simplify the calculation of $\mathrm{C}_{\text {int }}$ (in Watts), this has been modelled by Minetti and Saibene (24) as:

$$
\mathrm{C}_{\mathrm{int}}=\mathrm{SR} \cdot \mathrm{V}^{2} \frac{\pi^{2}}{2}\left[\left(\mathrm{a}^{2}+\mathrm{g}^{2}\right)\left(\mathrm{m}_{\mathrm{L}}+\mathrm{b}^{2} \mathrm{~m}_{\mathrm{U}}\right)\right]
$$

This equation shows that $\mathrm{C}_{\mathrm{int}}$ mainly depends on the $\mathrm{SR}$, and on the running speed (V). However other parameters influence $\mathrm{C}_{\mathrm{int}}$, including the mass of the lower and upper limb $\left(m_{L}\right.$ and $\left.m_{U}\right)$, the fractional distance of the lower limb centre of mass from the proximal joint (a), the length of the upper limb as a fraction of the lower limb one (b) and the average radius of gyration of limbs, as a fraction of the limb length (g).

\section{Paragraph Number 20}

Thus, the internal mechanical cost depends on the speed and on the mass of the segments, as well as on the segmental organisation during running. Using this equation, Borrani et al. (10) have recently showed that on the treadmill, $\mathrm{C}_{\text {int }}$ decreases significantly from $0.90(0.07)$ to $0.87(0.04) \mathrm{J} . \mathrm{kg}^{-1} \cdot \mathrm{m}^{-1}(3.5 \%)$ throughout the slowcomponent period. This decrease is mainly the result of the respective decrease in contact time $(-2.6 \%)$ and stride frequency $(-2 \%)$. Contrary to the results of Borrani et al. (10), the present study showed that $C_{\text {int }}$ increased within the third minute and the last minute of the exercise. This difference can be explained by the method used. Indeed, the study of Borrani et al. (10) was carried out on a treadmill whereas the present results have been obtained during over-ground running. Therefore the differences observed between both studies may be explained by specific mechanical adaptations induced by treadmill or over-ground running $(18,32)$. This increase in $C_{\text {int }}$ could be linked to an increase in the leg speed during the stride or to a change in the segmental organisation. The stability of SR, observed in the present study, was not 
consistent with an increase in the leg speed. $\mathrm{As}_{\mathrm{ke}}$ or $\mathrm{C}_{\mathrm{pe}}$, the stride rate (SR) was not modified during an exhaustive run. Therefore, during over-ground running, the lack of any change did not support a role for SR during fatigue as a mechanism for the increase in $\mathrm{C}_{\mathrm{r}}$, as previously proposed by Borrani et al. (10) and Avogadro et al. (2). Furthermore, two studies carried out in order to understand the possible influence of cadence on the increase of $\mathrm{C}_{\mathrm{r}}$ during strenuous exercise $(3,7)$ have already demonstrated that in cycling as in running, the increase of $\mathrm{C}_{\mathrm{r}}$ was not influenced by cadence.

\section{Paragraph Number 21}

Thus, the increase in $\mathrm{C}_{\mathrm{int}}$ after the $3^{\text {rd }}$ min of exercise could be related to a change in the geometric configuration of the segments of the body. One probable hypothesis would be connected to the effect of fatigue on the biomechanical stride characteristic $(21,31)$. These effects of fatigue on $\mathrm{C}_{\text {int }}$, could depend on the level of experience in running. Indeed, the Student test has showed that the great variability in the $\% \Delta C_{\text {int }}$ depends on the skill/experience of the runner. On track, the non specialists increase $\mathrm{C}_{\text {int }}$ by $20 \%$, within the $3^{\text {rd }}$ and the last minute of exercise, while the specialists increase it by only $4 \%$. However, it is difficult to identify segments responsible for these modifications. Indeed, the use of a global method of calculation of the mechanical work does not allow one to determine precisely the segments responsible for the observed modifications. Only the use of a local method of the calculation of the mechanical work such as the method of calculation of powers developed in joints would allow a better understanding of the observed mechanical modifications. One of the perspectives of the present work would be to study the effects of fatigue in the mechanical work calculated by the method of the joints moments. Hence, the observed modifications of the style could be explained. However, the use of the joints method 
in running is limited to the study of the power developed at the level of the joints of lower limbs $(5,36)$.

Paragraph Number 22

The present results showed that both $\mathrm{C}_{\mathrm{int}}$ and the energy cost of running $\left(\mathrm{C}_{\mathrm{r}}\right)$ increase within the $3^{\text {rd }}$ minute and the end of the supra-threshold exercise. However, contrarily to the hypothesis of the present study, the figure $4 \mathrm{C}$ showed that there was no correlation between $C_{r}$ and $C_{i n t}$. Indeed, the study of individual variations of $C_{r}$ and $\mathrm{C}_{\mathrm{int}}$ shows that some runners who displayed an increase in $\mathrm{C}_{\mathrm{int}}$ did not display an increase in $C_{r}$. This result showed that the increase of $C_{r}$ could not be related to the increase in $\mathrm{C}_{\mathrm{int}}$ and that two independent mechanisms might explain the increase in $\mathrm{C}_{\mathrm{r}}$ and in $\mathrm{C}_{\text {int }}$.

\section{Paragraph Number 23}

The results reported in this study showed that during track running, exhaustion has no effect on $\mathrm{C}_{\mathrm{pe}}$ or $\mathrm{C}_{\mathrm{ke}}$. Only the $\mathrm{C}_{\mathrm{r}}$ and $\mathrm{C}_{\mathrm{int}}$ increased significantly at the end of a supralactic threshold exhaustive run. However, the $\mathrm{C}_{\mathrm{r}}$ is only correlated with $\mathrm{C}_{\mathrm{ke}}$ and $\mathrm{C}_{\mathrm{pe}}$, and not with $C_{i n t}$. Thus, the increase in $C_{r}$ is not associated with a modification of the mechanical work produced in running. The increase in $\mathrm{C}_{\text {int }}$ after the $3^{\text {rd }}$ minute of exercise could be related to a change in the geometric configuration of the segments of the body. The geometric configuration might depend on the skill/experience of the runner. The modification of $\mathrm{C}_{\mathrm{int}}$ suggests that the technique of running is a basic component of the training of endurance runners and above all in fatigue status. However, the increase in $\mathrm{C}_{\text {int }}$ during over-ground running to exhaustion has yet to be explained.

\section{Acknowledgments}

The authors gratefully acknowledge the Fédération Française de Ski and Dr. Michel Tavernier for their assistance during the experiment. 


\section{References}

1. Aunola, S., and H. Rusko. Reproducibility of aerobic and anaerobic thresholds in 20-50 year old men. Eur. J. Appl. Physiol. 53: 260-266, 1984.

2. Avogadro, P., A. Dolenec, and A. Belli. Changes in mechanical work during severe exhausting running. Eur. J. Appl. Physiol. 90: 165-170, 2003.

3. Barstow, T. J., A. Jones, P. Nguyen, and R. Casaburi. Influence of muscle fiber type and pedal frequency on oxygen uptake kinetics of heavy exercise. $J$. Appl. Physiol. 81: 1642-50, 1996.

4. Barstow, T.J., and P. Mole. Linear and nonlinear characteristics of oxygen uptake kinetics during heavy exercise. J. Appl. Physiol. 71: 2099-2106, 1991.

5. Belli, A., H. Kyröläinen, and P. Komi. Moment and power of lower limb joints in running. Int. J. Sports Med. 23: 136-141, 2001.

6. Bernard, O., F. Maddio, S. Ouattara, C. Jimenez, A. Charpenet, B. Melin, and J. Bittel. Influence of the oxygen uptake slow component on the aerobic energy cost of high-intensity sub maximal treadmill running in humans. Eur. J. Appl. Physiol. 78: 578-585, 1998.

7. Billat, V., L. Mille-Hamard, B. Petit, and J.P. Koralsztein. The role of cadence on the VO2 slow component in cycling and running in triathletes. Int. J. Sports Med.20: 429-37, 1999.

8. Billat, V., R. Richard, V., Binsse, J.P., Koralsztein, and P., Haouzi. The V(O2) slow component for severe exercise depends on type of exercise and is not correlated with time to fatigue. J. Appl. Physiol. 85: 2118-24, 1998.

9. Billat V., J. Slawinski, V. Bocquet, A. Demarle, L. Laffite, P. Chassaing, and J.P. Koralsztein. Intermittent runs at the velocity associated with maximal oxygen uptake enables subjects to remain at maximal oxygen uptake for longer 
time than intense but submaximal runs. Eur. J. Appl. Physiol.81: 188-196, 2000.

10. Borrani, F., R. Candau, S. Perrey, G.Y. Millet, G.P. Millet, and J.D. Rouillon. Does the mechanical work in running change during the $\dot{\mathrm{VO}}_{2}$ slow component? Med. Sci. Sports Exerc. 35: 50-57, 2003.

11. Bourdin, M., A. Belli, L. Arsac, C. Bosco, J.R. Lacour. Effect of vertical loading on energy cost and kinematics of running in trained male subjects. $J$. Appl. Physiol. 79: 2078-85, 1995.

12. Candau, R., A. Belli, G, Millet, D, Georges, B, Barbier, J.D. Rouillon. Energy cost and running mechanics during a treadmill run to voluntary exhaustion in humans. Eur. J. Appl. Physiol. Occup. Physiol. 77: 479-85, 1998.

13. Carter, H., A. Jones, T. Barstow, M. Burnley, C. Williams, and H. Doust. Effect of endurance training on oxygen uptake kinetics during treadmill running. .J Appl. Physiol. 89: 1744-52, 2000.

14. Cavagna, G.A., and M. Kaneko. Mechanical work and efficiency in level walking and running. J. Physiol. 268: 647-81, 1977.

15. Dalleau G., Belli A., Bourdin M., Lacour J. R. The spring-mass model and the energy cost of treadmill running. Eur. J. Appl. Physiol. Occup. Physiol. 77: 257-63, 1998.

16. Dempster, W., and G., Gaughran. Properties of body segments based on size and weight. Am. J. Anat. 120: 33-54, 1967.

17. Donelan, J., D. Shipman, R. Kram, A. Kuo. Mechanical and metabolic requirements for active lateral stabilization in human walking. $J$. Biomech. 37: 827-835, 2004. 
18. Elliott, B.C., and B.A. Blanksby. A cinematographic analysis of overground and treadmill running by males and females. Med. Sci. Sports 8: 84-7, 1976.

19. Farley C., McMahon T. Energetics of walking and running : insights from simulated reduced-gravity experiments. J. Appl. Physiol. 73: 2709-2712, 1992.

20. Gaesser, G., and D. Poole. The slow component of oxygen uptake kinetics in humans. Exerc. Sports Sci. Rev. 24: 35-71, 1996.

21. Gazeau, F., J.P. Koralsztein, V. Billat. Biomechanical events in the time to exhaustion at maximum aerobic speed. Arch. Physiol. Biochem. 6: 1-8, 1997.

22. Kram R. Muscular force or work : what determine the metabolic energy cost of running ? Exerc. Sport Sci. Rev. 28: 138-143, 2000.

23. McFarlane, D. Automated metabolic gas analysis system. Sports Med.31: 841$861,2001$.

24. Minetti, A. A model equation for the prediction of mechanical internal work of terrestrial locomotion. J. Biomech. 31: 463-468, 1998.

25. Morgan, D.W., P.E. Martin, G.S. Krahenbuhl. Factors affecting running economy. Sports Med. 7: 310-30, 1989.

26. Poole, D.C., W. Schaffartzik, D.R. Knight, T. Derion, B. Kennedy, H. Guy, R. Prediletto, and P. Wagner. Contribution of excising legs to the slow component of oxygen uptake kinetics in humans. J. Appl. Physiol.71: 1245-60, 1991.

27. Slawinski, J., V. Billat, J.P. Koralsztein, and M. Taverner. Use of lumbar point for the estimation of potential and kinetic mechanical power in running. $J$. Appl. Biomech. 20: 324-331, 2004. 
28. Slawinski, J., and V. Billat. Difference in mechanical and energy cost between highly, well and non trained runners. Med. Sports Sci. Exerc.36: 1440-1446, 2004.

29. Slawinski, Jean. Effects of exhaustion and training level: study of the relationships between the energy cost of running and the mechanical cost of running. Doctoral dissertation. University of Evry Val d'Essonne, Dept. STAPS, France, June 2003.

30. Tavernier, M., P. Cosserat, A. Emmendoerffer, A. Ruby, J. Lavest, M. Dhome, and J.P. Verriest. A 3D motion analysis system using a numerical human model. In Proceedings of the International Society of Biomechanics Congress, Tokyo, Vol 19, pp. 406, 1997.

31. Verkerke, G., W. Ament, R. Wierenga, and G. Rakhorst. Measuring changes in step parameters during an exhausting running exercise. Gait and Posture. 8: 37-42, 1998.

32. Wank, V., U. Frick, and D. Schmidtbleicher. Kinematics and electromyography of lower limb muscles in overground and treadmill running. Int. J. Sports Med. 19: 455-461, 1998.

33. Whipp, B., and K. Wasserman. Oxygen uptake kinetics for various intensities of constant-load work. J. Appl. Physiol.33: 351-356, 1972.

34. Willems, P., G. Cavagna, and N. Heglund. External, internal and total work in human locomotion. J. Exp. Biol. 198: 379-393, 1995.

35. Williams, K., and P. Cavanagh. Relationship between distance running mechanics, running economy, and performance. J. Appl. Physiol. 63: 1236$1245,1987$. 
36. Winter, D. Moments of force and mechanical power in jogging. J. Biomech.16: 91-97, 1980.

37. Winter D. Biomechanics and motor control of human movement. John Wiley, New York, pp 39-41, 1992.

38. Xu, F., and E. Rhodes. Oxygen uptake kinetics during exercise. Sports Med. 27: 313-27, 1999. 